\title{
Epidemiological profile of drowning deaths: a cross sectional study
}

\author{
Laxman Gangadhar Phad ${ }^{1}$ and Shailendra G. Dhawane ${ }^{2^{*}}$
}

\begin{abstract}
Background: World Health Organization described, drowning as serious and neglected public health problem. Near about 42 people every hour and 3.7 lakh every year die from drowning in the world. In India out of total cases of unnatural deaths $9.4 \%$ were died due to drowning, this was the second most common after road traffic accidents.

Method: The present study was undertaken at tertiary care hospital government medical college and hospital located in central India on dead bodies brought for postmortem. The study was carried out during the period of December 2013 to November 2015 on 176 cases, to study the various epidemiological parameters of drowning.

Result and conclusions: We have concluded that $72.02 \%$ victims were male and $28.98 \%$ were female, with ratio 2.45 : 1 , drowning deaths were most commonly seen in age groups of 21-30 years (27.84\%). Married population constitutes 46.59\% and remaining 32.95\% were unmarried. Maximum number of drowning deaths had occurred in urban region constituting $57.38 \%$ cases followed by rural region constituting $42.62 \%$ cases. Students were the victim seen in $18.75 \%$ cases, Hindu community contributed to maximum number of cases with $60.23 \%$ cases, number of victims of drowning deaths belong to upper-lower class with $35.23 \%$ cases. In drowning deaths $21.02 \%$ of victims had familial and financial problems and depression in $20.45 \%$ cases, chronic alcoholism in $18.18 \%$ cases. The number of drowning deaths occurred in rainy season was (43.75\%). Most of the drowned victims were retrieved from lakes (44.32\%), wells (34.66\%), rivers (8.52\%) and ponds (5.68\%).
\end{abstract}

Keywords: Drowning deaths, Source of drowning, Socioeconomic status, Seasonal variation

\section{Background}

The well-known saying that "Water is life" itself reveals the fact that, there will be no existence of life without water. Millions of years ago, the first appearance of life on earth had occurred in water (The Archean, Paleobiology.si.edu 2014). In addition to its life sustaining role, water is one of the most destructive forces on earth in the form of tsunamis and flood disasters, which are responsible for the loss of life on a large scale. On the other hand, famine had claimed millions of lives in the world many times (Encyclopedia of earth, Eoearth.org 2014). So it could be said that water is a 'double edged sword'.

World Health Organization (WHO) had adopted the new definition at the first world congress on drowning in 2002 as "Drowning is the process of experiencing respiratory impairment from submersion or immersion

\footnotetext{
* Correspondence: laxmanphad25@gmail.com

2Department of Forensic Medicine, GMCH Chandrapur, Maharashtra, India Full list of author information is available at the end of the article
}

in liquid."(World Health Organization 2014) World Health Organization (WHO) described drowning is one of the top five causes of death in children aged between 1 and 14 years and one of the ten leading causes of death in children and young people aged between 1 and 24 years (World Health Organization 2014). Homicidal drowning accounts for $20 \%$ of all U.S. killings. Amongst the homicidal drowning, most cases are children drowned by their parents, or wives drowned by their husbands in a bathtub. According to Federal Bureau of Investigation (FBI) data United States had recorded 907 homicidal drowning deaths over the course of 21 years, of these 416 (45\%) cases seen below the age of eight years, followed by college students $117(12 \%)$ cases, of aged between 18 and 24 years (Dallas et al. 2010).

Rate of drowning death is 82 cases per day in India (Accidental deaths and suicidal deaths in India 2013 statistics, National crime records bureau 2014). National Crime Records Bureau (NCRB) data 2014 stated that, 
out of 316,828 cases of unnatural deaths, 29,903 cases (9.4\%) died due to drowning in which 23,166 cases (77.47\%) were male, 6736 cases $(22.52 \%)$ were females and 1 case $(0.0033 \%)$ was transgender; this was the second most common cause of unnatural death after road traffic accidents (53.4\%). Amongst the total number of drowning deaths, near about 11,884 cases (39.74\%) died due to accidental fall in water, 7426 cases (5.6\%) died due to suicidal drowning (Accidental deaths and suicidal deaths in India 2014 statistics, National crime records bureau 2014).

\section{Material and methods}

The present study was undertaken at tertiary care hospital, government medical college and hospital Nagpur located in central India, where yearly near about 3000 medicolegal autopsies were carried out. We have carried out study on epidemiological profile of the drowning deaths in 176 cases excluding bodies in advanced state of decomposition. The study was carried out over the period of December 2013 to October 2015, with the aim of studying various epidemiological parameters. The study includes, only the dead bodies which were retrieved from water sources and having history of drowning, brought for post mortem examination. As per law of the land, consent of relatives is not required for carrying out the medicolegal postmortem examination on the corpse of the deceased; hence it was not necessary to obtain consent from relatives or any other authority in this particular study. However, as per the prevailing mandatory standard procedures of the Institute, the prior permission cum no objection certificate to carry out the study was obtained from local ethical committee. Detailed history and relevant information was collected from police inquest and requisition (Panchanama) regarding the age, sex, address, marital status, mental status, occupation, education, religion, supposed cause of and eye witness of incidence etc., and if the relatives were present at the time of postmortem examination, necessary information was collected regarding the personal, mental and behavioral aspect.

\section{Result}

\section{Age and gender}

The drowning deaths were commonly seen in age groups of 21-30 years (27.84\%) followed by $31-40$ years $(22.73 \%)$ and $41-50$ years $(18.75 \%)$. Predominance of male was seen in all age groups in drowning death except in the age group 0-10 years age group and 5070 year age group shows female predominance with $13.73 \%$ cases in both. Among the total cases, $71.02 \%$ victims were male and $28.98 \%$ were female. The male: female ratio was 2.45:1 Table 1, Fig. 1.
Table 1 Age and Gender distribution of drowning deaths

\begin{tabular}{|c|c|c|c|c|c|c|}
\hline \multirow{2}{*}{$\begin{array}{l}\text { Age } \\
\text { (In } \\
\text { Years) }\end{array}$} & \multicolumn{2}{|l|}{ Male } & \multicolumn{2}{|c|}{ Female } & \multicolumn{2}{|l|}{ Total } \\
\hline & Cases & $\%$ & Cases & $\%$ & Cases & $\%$ \\
\hline $0-10$ & 3 & 2.40 & 7 & 13.73 & 10 & 5.68 \\
\hline $11-20$ & 13 & 10.40 & 5 & 9.80 & 18 & 10.23 \\
\hline $21-30$ & 38 & 30.40 & 11 & 21.57 & 49 & 27.84 \\
\hline $31-40$ & 32 & 25.60 & 8 & 15.69 & 40 & 22.73 \\
\hline $41-50$ & 24 & 19.20 & 9 & 17.65 & 33 & 18.75 \\
\hline $51-60$ & 6 & 4.80 & 7 & 13.73 & 13 & 7.39 \\
\hline $61-70$ & 6 & 4.80 & 3 & 5.88 & 9 & 5.11 \\
\hline$>70$ & 3 & 2.40 & 1 & 1.96 & 4 & 2.27 \\
\hline Total & 125 & $100(71.02)$ & 51 & $100(29.98)$ & 176 & 100 \\
\hline
\end{tabular}

\section{Marital status}

As per marital status, $46.59 \%$ victims were married and $32.95 \%$ were unmarried. Among the females 56.86\% were married and (25.49\%) were unmarried, and among the males $42.40 \%$ were married and were (36\%) unmarried. And remaining cases status is not known Fig. 2.

\section{Region of occurance}

Maximum number of drowning deaths had occurred in urban region constituting $57.38 \%$ cases followed by rural region constituting $42.62 \%$ cases. In urban region, the male $(59.20 \%)$ drowning deaths are more as compared to females $(52.94 \%)$, whereas in rural region the females (47.06\%) drowning death are more as compared to males (40.80\%) Fig. 3.

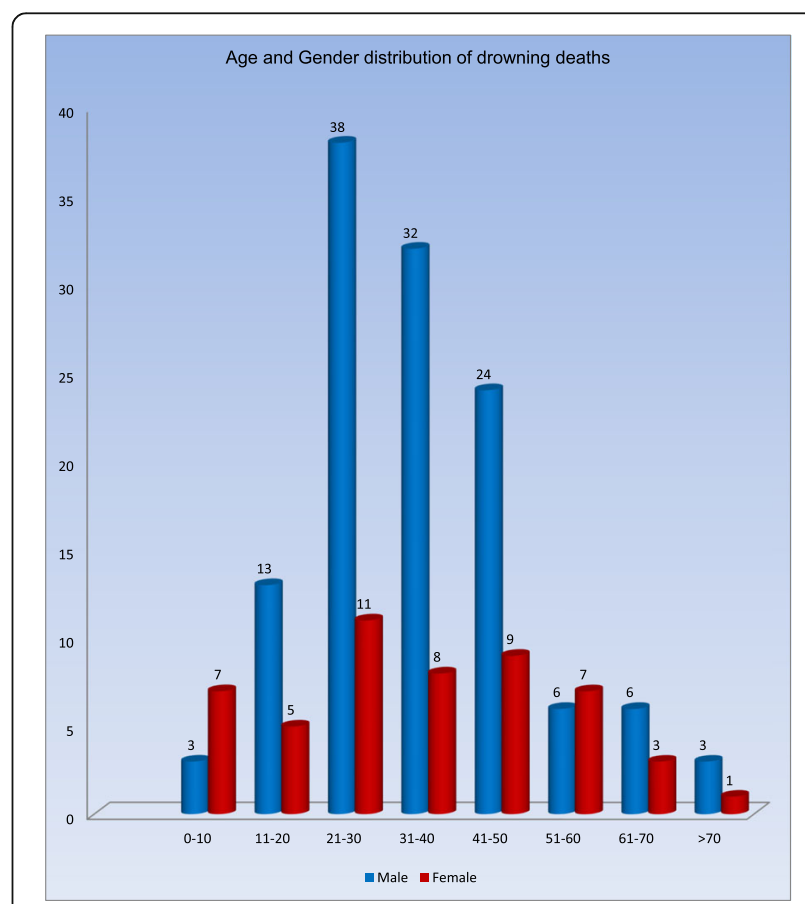

Fig. 1 Age and Gender distribution of drowning deaths 


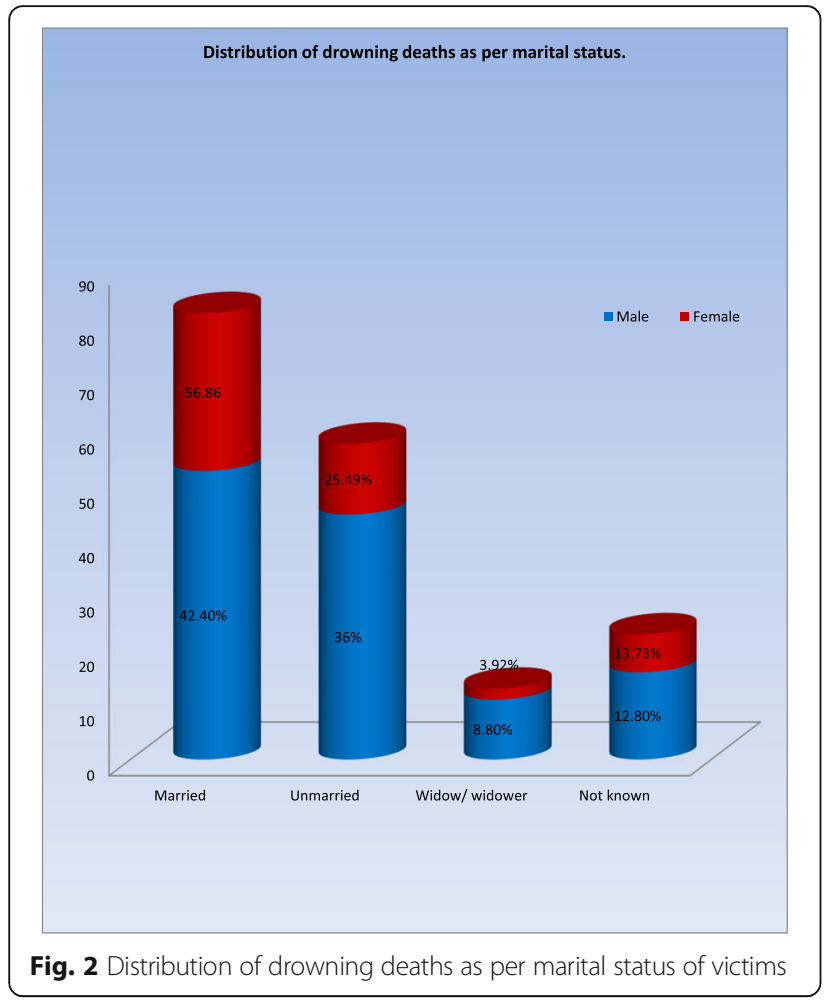

\section{Occupation}

Students were the most common victims in drowning deaths seen in $18.75 \%$ cases, followed by non-working victims in $17.62 \%$ cases, farmer in $16.48 \%$ cases and labourer in $11.36 \%$ cases Table 2.

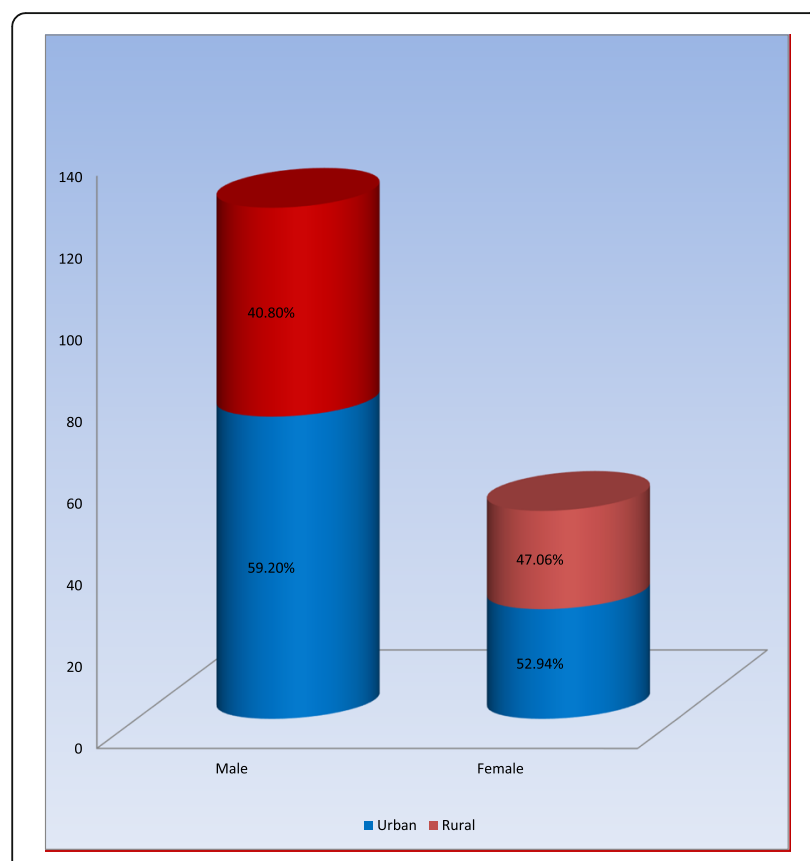

Fig. 3 Distribution of drowning deaths as per region of occurrence
Table 2 Distribution of drowning deaths according to occupation

\begin{tabular}{|c|c|c|c|c|c|c|}
\hline \multirow[t]{2}{*}{ Occupation } & \multicolumn{2}{|l|}{ Male } & \multicolumn{2}{|c|}{ Female } & \multicolumn{2}{|l|}{ Total } \\
\hline & Cases & $\%$ & Cases & $\%$ & Cases & $\%$ \\
\hline Student & 24 & 19.20 & 9 & 17.65 & 33 & 18.75 \\
\hline Farmer & 17 & 13.60 & 12 & 23.53 & 29 & 16.48 \\
\hline Labourer & 17 & 13.60 & 3 & 5.88 & 20 & 11.36 \\
\hline Service & 17 & 13.60 & 0 & 0.00 & 17 & 9.66 \\
\hline House wife & 0 & 0.00 & 16 & 31.37 & 16 & 9.09 \\
\hline Business & 9 & 7.20 & 0 & 0.00 & 9 & 5.11 \\
\hline Non-working & 26 & 20.80 & 5 & 9.80 & 31 & 17.62 \\
\hline Not known & 15 & 12.00 & 6 & 11.77 & 21 & 11.93 \\
\hline Total & 125 & 100 & 51 & 100 & 176 & 100 \\
\hline
\end{tabular}

\section{Religion}

Hindu community contributed to maximum number of cases with $60.23 \%$ cases, followed by Buddhist in $18.75 \%$; Muslim in $6.25 \%$, Jain in $1.14 \%$, Christian in $0.57 \%$ cases Fig. 4.

\section{Socioeconomic status}

Depending on the socioeconomic status, most of the victims of drowning deaths belong to upper-lower class seen in $35.23 \%$ followed by lower class in $20.45 \%$ cases and lower middle class in $14.77 \%$ cases, and $6.25 \%$ of the victims of drowning death belong to upper class of socioeconomic status Table 3.

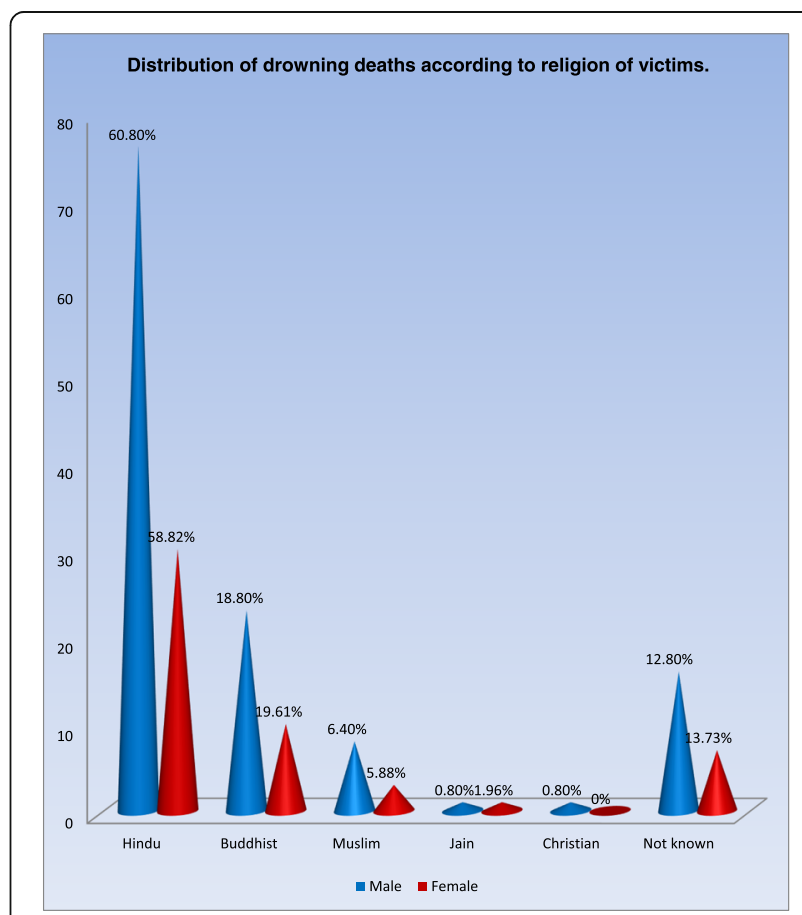

Fig. 4 Distribution of drowning deaths according to religion of victims 
Table 3 Distribution of drowning deaths as per socioeconomic status

\begin{tabular}{|c|c|c|c|c|c|c|}
\hline \multirow{2}{*}{$\begin{array}{l}\text { Socioeconomic } \\
\text { status }^{a}\end{array}$} & \multicolumn{2}{|l|}{ Male } & \multicolumn{2}{|c|}{ Female } & \multicolumn{2}{|l|}{ Total } \\
\hline & Cases & $\%$ & Cases & $\%$ & Cases & $\%$ \\
\hline I / Upper class & 5 & 4.00 & 6 & 11.76 & 11 & 6.25 \\
\hline $\begin{array}{l}\text { I / Upper middle } \\
\text { class }\end{array}$ & 17 & 13.60 & 1 & 1.97 & 18 & 10.23 \\
\hline $\begin{array}{l}\text { III / Lower middle } \\
\text { class }\end{array}$ & 17 & 13.60 & 9 & 17.64 & 26 & 14.77 \\
\hline $\begin{array}{l}\text { IV / Upper lower } \\
\text { class }\end{array}$ & 48 & 38.40 & 14 & 27.45 & 62 & 35.23 \\
\hline V / Lower class & 22 & 17.60 & 14 & 27.45 & 36 & 20.45 \\
\hline Not known & 16 & 12.80 & 7 & 13.73 & 23 & 13.07 \\
\hline Total & 125 & 100 & 51 & 100 & 176 & 100 \\
\hline
\end{tabular}

${ }^{a}$ Acoordong to B.G. Prasad's classification for rural and modified Kuppuswami's classification for urban population

\section{Personal history}

In drowning deaths $21.02 \%$ of victims had familial and financial problems. The second most common history associated with drowning death was depression seen in $20.45 \%$ cases, followed by chronic alcoholism in $18.18 \%$ cases and chronic illness in $17.61 \%$ cases. Male predominance was seen in almost all of the associated history except psychiatric illness (7.38\%) in which female outnumbered male in drowning deaths Table 4.

\section{Seasonal variation}

The maximum number of drowning deaths occurred in rainy season $(43.75 \%)$. This was followed by summer season (32.95\%) and winter season (23.30\%) Fig. 5.

\section{Place of occurrence}

Most of the drowned victims were retrieved from lakes (44.32\%), followed by wells (34.66\%), rivers $(8.52 \%)$ and ponds $(5.68 \%)$. Most of the male victims was retrieved from lake $(53.60 \%)$ followed by well in $29.60 \%$ cases, but most of the female victims was retrieved from the well $(47.05 \%)$ followed lakes $(21.56 \%)$ by river in $11.76 \%$.

Table 4 Distributions of drowning deaths as per personal history $(n=176)$

\begin{tabular}{|c|c|c|c|c|c|c|}
\hline \multirow[t]{2}{*}{ Personal History } & \multicolumn{2}{|c|}{$\begin{array}{l}\text { Male } \\
(n=125)\end{array}$} & \multicolumn{2}{|c|}{$\begin{array}{l}\text { Female } \\
(n=51)\end{array}$} & \multicolumn{2}{|c|}{$\begin{array}{l}\text { Total } \\
(n=176)\end{array}$} \\
\hline & Cases & $\%$ & Cases & $\%$ & Cases & $\%$ \\
\hline $\begin{array}{l}\text { Familial and Financial } \\
\text { problems }\end{array}$ & 27 & 21.60 & 10 & 19.60 & 37 & 21.02 \\
\hline Depression & 31 & 24.80 & 5 & 9.80 & 36 & 20.45 \\
\hline Chronic alcoholism & 32 & 25.60 & 0 & 0.00 & 32 & 18.18 \\
\hline Chronic illness & 18 & 14.40 & 13 & 25.49 & 31 & 17.61 \\
\hline Psychiatric illness & 5 & 4.00 & 8 & 15.68 & 13 & 7.38 \\
\hline Failure in love & 4 & 3.20 & 2 & 3.92 & 6 & 3.40 \\
\hline Epilepsy & 0 & 0.00 & 1 & 1.96 & 1 & 0.56 \\
\hline
\end{tabular}

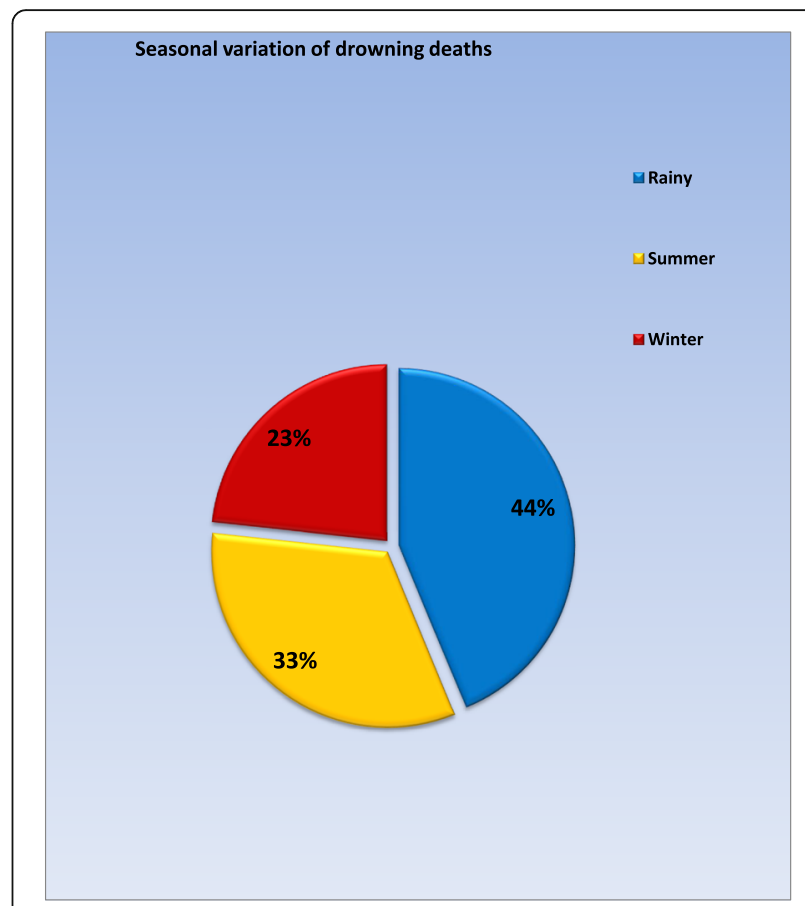

Fig. 5 Seasonal variation of drowning deaths

Rarely the body was found in swimming pool, water tank, canal (gutter) and water tub Table 5.

\section{Discussion}

The drowning deaths were predominantly seen in male (71.02\%) with male: female ratio of $2.45: 1$, they were commonly seen in age groups of $21-30$ years $(27.84 \%)$ followed by 31- 40 years and 41-50 years. Predominance of male was seen in all age groups except below 10 years and between 50 and 70 years of age. These findings are consistent with that of Auer (1990), Quan (2003), Suresh Kumar Shetty and Shetty (2007), Pathak and Mangal

Table 5 Distribution of drowning deaths as per place of retrieval of body (source of drowning)

\begin{tabular}{|c|c|c|c|c|c|c|}
\hline \multirow{2}{*}{$\begin{array}{l}\text { Place of } \\
\text { retrieval } \\
\text { (Source) }\end{array}$} & \multicolumn{2}{|l|}{ Male } & \multicolumn{2}{|c|}{ Female } & \multicolumn{2}{|l|}{ Total } \\
\hline & Cases & $\%$ & Cases & $\%$ & Cases & $\%$ \\
\hline Lake & 67 & 53.60 & 11 & 21.56 & 78 & 44.32 \\
\hline Well & 37 & 29.60 & 24 & 47.05 & 61 & 34.66 \\
\hline River & 9 & 7.20 & 6 & 11.76 & 15 & 8.52 \\
\hline Pond & 5 & 4.00 & 5 & 9.80 & 10 & 5.68 \\
\hline $\begin{array}{l}\text { Swimming } \\
\text { pool }\end{array}$ & 4 & 3.20 & 1 & 1.97 & 5 & 2.84 \\
\hline $\begin{array}{l}\text { Canal } \\
\text { (Gutter) }\end{array}$ & 2 & 1.60 & 1 & 1.97 & 3 & 1.70 \\
\hline Water tank & 1 & 0.80 & 1 & 1.97 & 2 & 1.14 \\
\hline Water Tub & 0 & 0.00 & 2 & 3.92 & 2 & 1.14 \\
\hline Total & 125 & 100 & 51 & 100 & 176 & 100 \\
\hline
\end{tabular}


(2009) and Saberi Anary et al. (2010). The probable reason behind preponderance of 21-30 years age group in drowning is carelessness and adventurous nature usually seen in youngsters while swimming or doing recreational activities in or around water source leading to accidental deaths. This is followed by the age group of 31-40 years, it may be due to familial and financial problems arising in life and their inability to deal with them.

As per marital status, $46.59 \%$ victims were married and $32.95 \%$ were unmarried. Among the females 56.86\% were married and (25.49\%) were unmarried, and among the males $42.40 \%$ were married and were $(36 \%)$ unmarried. And remaining cases status is not known. It may be due to over exposure of married and working people in and around water sources leading to accidental deaths. Also they prefer to commit suicide by drowning due to inability to handle familial and financial problems. This finding is consistent with that of Gorea and Singh (2005), Ranga Rao et al. (2014) who found 38\% and 50\% married victims respectively who died of drowning.

Maximum number of drowning deaths had occurred in urban region constituting $57.38 \%$ cases followed by rural region constituting $42.62 \%$ cases. In urban region, the male (59.20\%) drowning deaths are more as compared to females (52.94\%), whereas in rural region the females $(47.06 \%)$ drowning death are more as compared to males $(40.80 \%)$. These findings are in contrast to study carried out by Delmonte and Capelozzi (2001) and Murkey et al. (2008), this may be due to different region of study. The present study was carried out in urban region in contrast to Murkey et al. (2008) and Delmonte and Capelozzi (2001) which was conducted in rural region.

The most common victims of drowning deaths were the student seen in $18.75 \%$ cases. It may be due to carelessness and adventurous nature usually seen in youngsters while swimming or doing recreational activities in or around water source. This is followed by non-working victims in $17.62 \%$ cases, farmers in $16.48 \%$ cases and labourer in $11.36 \%$ cases; it is probably due to financial and familial problems,

Hindu community contributes to maximum number of cases with $60.23 \%$, followed by Buddhist in 18.75\%; Muslim in $6.25 \%$, Jain in $1.14 \%$, Christian in $0.57 \%$ cases. In $13.06 \%$ cases, the religion of victim was not known. This is due to the predominance of the Hindu population where the study was carried out. Pathak and Mangal (2009) also found that $90.69 \%$ of the victims of drowning deaths belong to Hindu community, followed by Muslim community in $6.98 \%$ cases and Sikh community in $2.33 \%$ cases.

Depending on the socioeconomic status, most of the victims of drowning deaths belong to upper-lower class seen in $35.23 \%$ followed by lower class in $20.45 \%$ cases, lower middle class in $14.77 \%$ cases upper class in $6.25 \%$ cases. In $13.07 \%$ cases, the socioeconomic status of the victims of drowning deaths was not known.

$21.02 \%$ of victims of drowning death had familial and financial problems. The second most common history associated with drowning death was depression seen in $20.45 \%$ cases. This is followed by chronic alcoholism in $18.18 \%$ cases and chronic illness in $17.61 \%$ cases. Male predominance was seen in almost all the associated history except psychiatric illness $(7.38 \%)$ in which female (15.68\%) outnumbered male (4\%) in drowning death. The present study is in accordance with Dietz and Baker (1974), Auer (1990), Fralick et al. (2013).

The maximum number of drowning deaths occurred in rainy season $(43.75 \%)$. This is followed by summer season $32.95 \%$ cases and winter season $23.30 \%$ cases. This finding is consistent with Pathak and Mangal (2009), Job (2009), Ambade et al. (2013) studies where maximum drowning deaths were found in rainy season.

Most of the drowned victims were retrieved from lake in $44.32 \%$ cases. This is followed by well in $34.66 \%$ cases, river in $8.52 \%$ cases, and pond in $5.68 \%$ cases. Most of the male victims was retrieved from lake $(53.60 \%)$ followed by well in $29.60 \%$ cases, but most of the female victims was retrieved from the well $(47.05 \%)$ followed by lake (21.56\%) river in $11.76 \%$. Rarely the body was found in swimming pool, water tank, canal (gutter) and water tub. The present study is in accordance with Patetta (1988), Bose et al. (2000), Quan (2003), Fralick et al. (2013) and Ranga Rao et al. (2014).

\section{Summary and conclusion}

In above study we concluded that, Male predominance seen in drowning deaths with highest incidence seen in third and fourth decades. Drowning deaths are most common in urban region followed by rural region. Students are the most common victims of drowning deaths followed by non-working, farmers and laborers. Drowning deaths are most commonly found in Hindu community followed by Buddhist and Muslims. Drowning deaths are most common in married people as compared to unmarried people. Drowning deaths are most commonly found in upper lower class, followed by lower class, lower middle class and upper middle class. Familial and financial problems is the most common history seen in drowning deaths followed by depression, chronic alcoholism, chronic illness and psychiatric illness. Drowning deaths are most common in rainy season followed by summer and winter season. Lake is the most common place from where the bodies were retrieved followed by well, river and pond. 


\section{Abbreviations}

FBI: Federal Bureau of Investigation; NCRB: National Crime Records Bureau; U.S.: United States; WHO: World Health Organization

\section{Acknowledgements}

Authors gratefully thank Dr. P.G.Dixit sir, Professor and Head of the department for granting permission for the study and continuous encouragement and guidance throughout the study.

\section{Funding}

No funding was received for this research study.

\section{Availability of data and materials}

The study was undertaken on the bodies brought for routine medicolegal postmortem examination forensic medicine department. The police inquest papers, personal information forms filled by police with the help of relatives and the findings noted wile doing postmortem examination by me are t6he data sources.

\section{Authors' contributions}

Both authors have contributions in study. The study was conducted by LGP under guidance of SGD. Both authors read and approved the final manuscript.

\section{Ethics approval and consent to participate}

The study was undertaken by me as dissertation study while doing Postgraduation in MD- FORENSIC MEDICINE.

The study was approved by institutional ethics committee Government medical college Nagpur. Reg. no. ECR/ 43/ inst/MH/2013 consisting chairman, vice chairman and secretary members. And certificate letter was issued for the study with their signature.

The proposal for study was sent to MAHARASHTRA UNIVERSITY OF HEALTH SCIENCES for further approval and the study was approved. With reference no. MUHS/PG-T/E1/FL.42/2690/2014 Dated:09/10/2014. And certificate letter was issued for the study with their signature.

In India, consent of relatives is not required for carrying out the medicolegal postmortem examination its right of investigating authority so, the police inquest and requisition letter have been taken to carry out postmortem examination. The study was undertaken on the bodies brought for routine medicolegal postmortem examination.

\section{Consent for publication}

Not applicable.

\section{Competing interests}

The authors declare that they have no competing interests.

\section{Publisher's Note}

Springer Nature remains neutral with regard to jurisdictional claims in published maps and institutional affiliations.

\section{Author details}

'Department of Forensic Medicine, GMCH Aurangabad, Maharashtra, India. 2Department of Forensic Medicine, GMCH Chandrapur, Maharashtra, India.

Received: 19 June 2017 Accepted: 28 February 2018

Published online: 10 March 2018

\section{References}

Accidental deaths and suicidal deaths in India 2013 statistics, National crime records bureau. Ministry of home affairs. [Internet] [cited 20 December 2014] retrieved from: http://ncrb.gov.in/StatPublications/ADSI/ADSI2013/ADSI2013.htm

Accidental deaths and suicidal deaths in India 2014 statistics, National crime records bureau. Ministry of home affairs. [Internet] [cited 28 December 2014] retrieved from: http://ncrb.gov.in/ADSI2014/adsi-2014,20full,20report.pdf

Ambade V, Kukde H, Malani A, Tumram N, Borkar J, Batra A et al (2013) Decomposed and non-decomposed bodies retrieved from water: a comparative approach. Med Sci Law. 53:12-18

Auer A (1990) Suicide by drowning in Uusimaa Province in southern Finland. Med Sci Law 30(2):175-179
Bose A, George K, Joseph A (2000) Drowning in childhood: a population based study. Indian Pediatr 37:80-83

Dallas D, Cheryl M, Brandon J, Wheeler, Eden Z, Stelflug, et al. Drowning the Smiley Face Murder Theory, Homicide Research Center [Internet]. Homicide Research Center. 2010 [cited 13 December 2014]. Center for Homicide Research, Available from: http://homicidecenter.org/publication/drowningthe-smiley-face-murder-theory/

Delmonte C, Capelozzi VL (2001) Morphologic determinants of asphyxia in lung: a semiquantitative study in forensic autopsies. Am J Forensic Med Pathol 22(2):139-149

Dietz P, Baker S (1974) Drowning: epidemiology and prevention. Am J Public Health 64(4):303-312

Encyclopedia of earth, Eoearth.org. Water [Internet]. [Retrieved on 25 September 2014] Available from: www.eoearth.org/view/article/157013/

Fralick M, Denny C, Redelmeier D (2013) Drowning and the influence of hot weather. PLoS One 8(8):e71689

Gorea R, Singh A (2005) Prevention of drowning and its societal implications. J Indian Academy of Forensic Medicine 27(4):240-242

Job C (2009) Determination of cause of death in decomposed bodies- a regional study. Journal Indian Academy Forensic Medicine. 31(1):11-17

Murkey P et al (2008) Drowning cases in Kasturba Hospital, M.G.I.M.S, Sewagram, Wardha, Maharashtra. Indian Journal of Forensic Medicine and Pathology 1(1):13-17

Patetta M (1988) Characteristics of drowning deaths in North Carolina. Public Health Rep 103(4):406-411

Pathak A, Mangal H (2009) Decomposition: cast shadow over the drowning deaths. Journal Indian Academy Forensic Medicine 31(2):112-117

Quan L (2003) Characteristics of drowning by different age groups. Injury Prevention 9(2):163-168

Ranga Rao G, Surendar J, Prasad G (2014) A comprehensive study ofdrowning in and around Kakinada, two years retrospective study. Scholars Journal of Applied Medical Sciences (SJAMS) 2(4D):1397-1401

Saberi Anary S, Sheikhazadi A, Ghadyani M (2010) Epidemiology of drowning in Mazandaran Province, north of Iran. Am J Forensic Med Pathol 31(3):236-242

Suresh Kumar Shetty B, Shetty M (2007) Epidemiology of drowning in Mangalore a coastal taluk of South India. J Forensic Legal Med 14(7):410-415

The Archean, Paleobiology.si.edu. Archean: The First Life on Earth [Internet] [Retrieved on 14 September 2014] Available from: http://paleo biology.si.edu/ geotime/main/htmlversion/archean3.html

World Health Organization (2014) Global report on drowning, preventing a leading killer, World Health Organization, http://www.who.int/violence_ injury_prevention/publications/drowning_global_report/Final_report_full_ web.pdf

\section{Submit your manuscript to a SpringerOpen ${ }^{\circ}$ journal and benefit from:}

- Convenient online submission

Rigorous peer review

- Open access: articles freely available online

- High visibility within the field

Retaining the copyright to your article

Submit your next manuscript at $>$ springeropen.com 